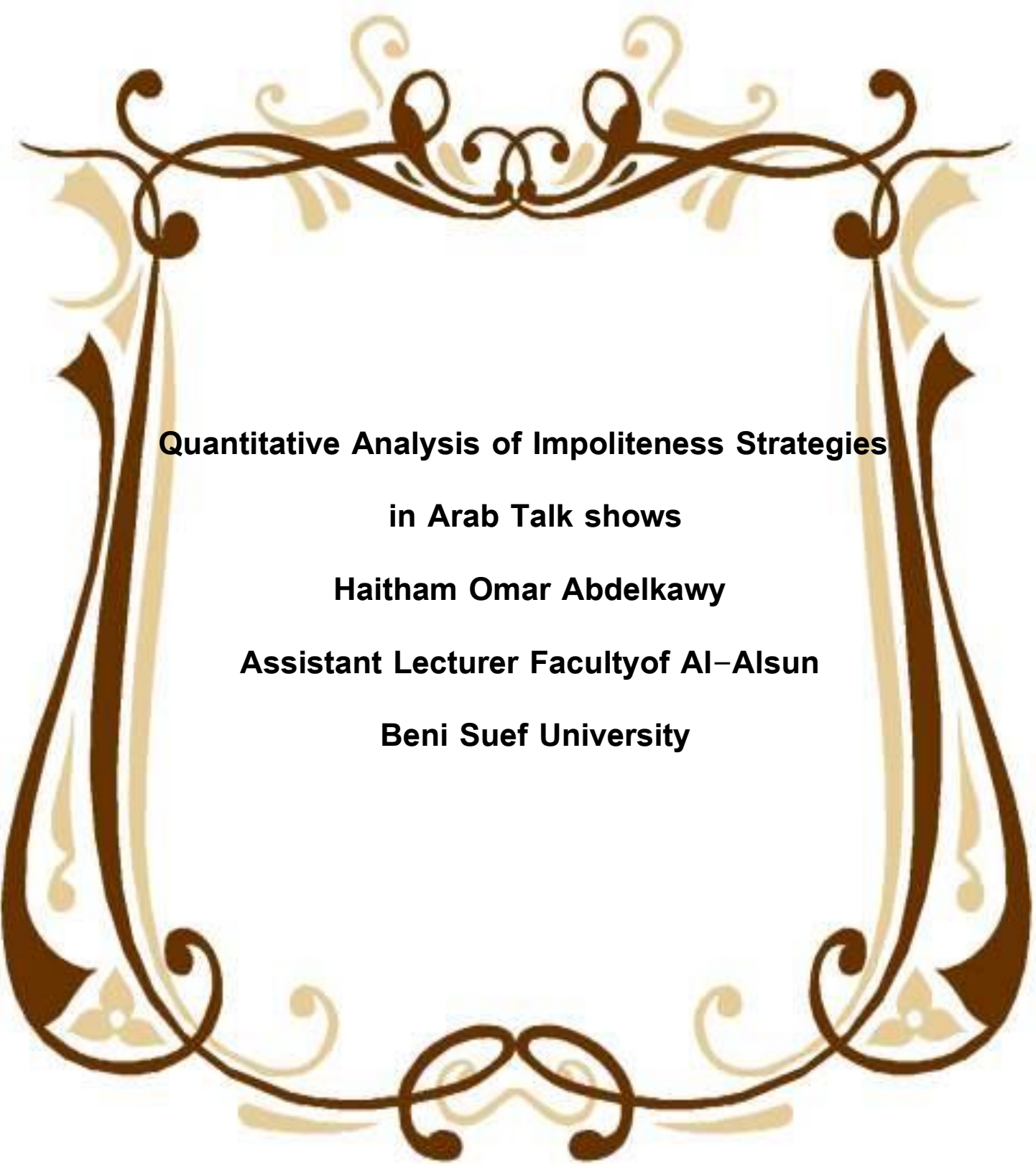




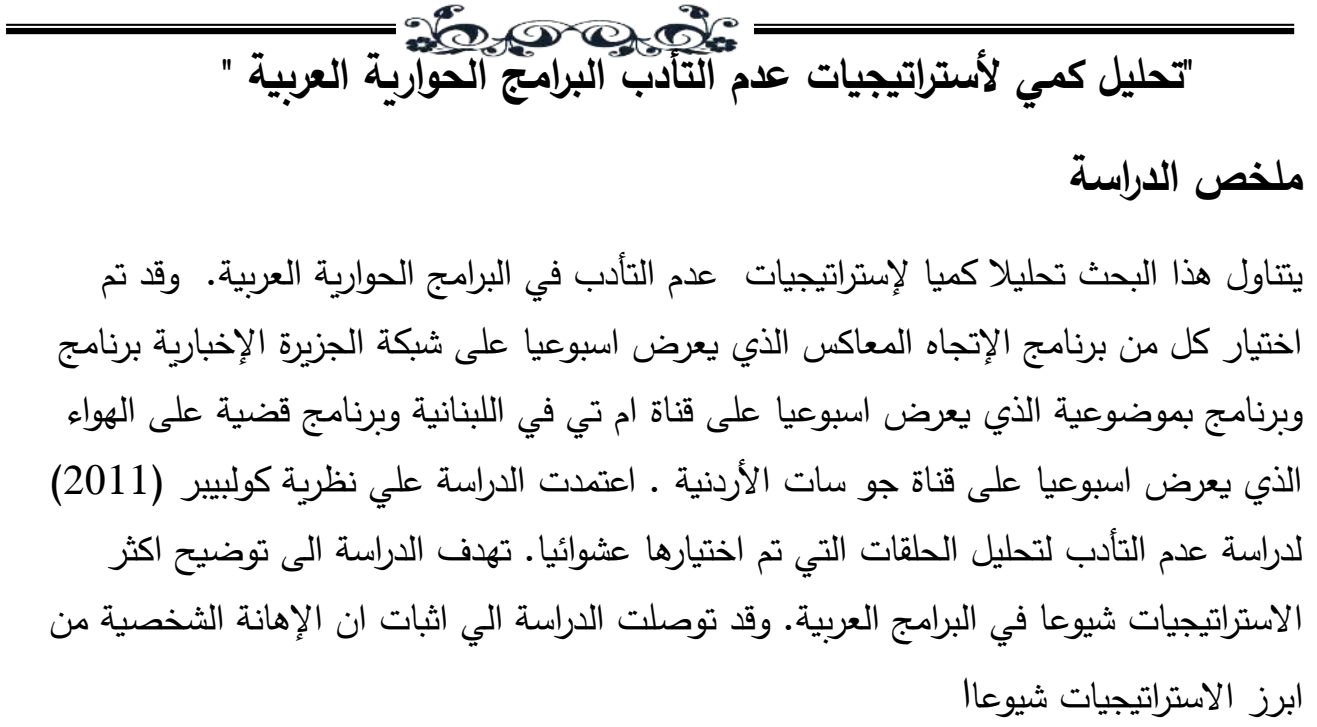

\section{Quantitative Analysis of Impoliteness Strategies in Arab}

\section{Talk shows}

\section{Abstract}

This study aims at analyzing the common impoliteness strategies in Arab television political talk shows. Twelve episodes from three Arab television political talk shows have been selected; the Opposite Direction, Issue on Air, and Objectivity. Culpeper's (2011) model for analyzing impoliteness is used. The study revealed that the strategies that are found in the episodes covering all the categories in the model, but in different rates. The highest rates are for insults and pointed Criticisms, which shows that the interlocutors intend to personalize the issue to humiliate each other. 


\section{Subject of the study}

This study tackles selected major Arab political talk-show program with the aim of revealing the most common impoliteness strategies. It tries to answer the following question:

1- What are some of the most common impoliteness strategies employed by guests in Arab political talk shows?

\section{Hypotheses}

The study hypothesizes that Arab talk show programs are rich in impoliteness and that "insult" may be the most common impoliteness strategy because of the quarrels that occur between interlocutors supporting contradicting points of view.

\section{Significance of the study}

Impoliteness studies lack applied research; this study may be a contribution to the applied research of impoliteness. Besides, it can be considered one of the earliest studies to examine impoliteness strategies in the discourse of Arab talk shows quantitatively.

\section{Methodology}

4. 1. Data collection

The data of this study consists of twelve episodes selected randomly from three famous Arab talk shows. The talk shows are The Opposite Direction, Objectivity, and Issue on Air.

\section{2. Methods of analysis}

This study applies Culpeper's (2011) impoliteness model to study impoliteness strategies quantitatively in three Arab talk-shows. There is one thing very important to bear in mind regarding this model which is context. The addresser must 
have the intention to insult the target, who in turn must perceive the utterance as an offense. If the utterance is taken as friendly banter, it cannot be regarded as impoliteness.

The following section is a summary of the model:

insults

1. Personalized negative vocatives

- [you] [fuck-

ing/rotten/dirty/fat/little/etc.][moron/fuck/plonker/dickhead/b erk/pig/shit/

bastard/loser/liar/minx/brat/slut/squirt/sod/bugger etc.] [you]

2. Personalized negative assertions

- [you] [are] [so/such a]

[shit/stink/thick/stupid/bitchy/bitch/hypocrite/disappointmen t/

gay/nuts/nuttier than a fruit

cake/hopeless/pathetic/fussy/terrible/fat/ugly/etc.]

- [you] [can't do] [anything right/basic arithmetic/etc.]

- [you] [disgust me]/ [make me] [sick/etc.]

3. Personalized negative references

- [your] [stinking/little]

[mouth/act/arse/body/corpse/hands/guts/trap/breath/etc.]

4. Personalized third-person negative references (in the hearing of the target)

- [the] [daft] [bimbo]

- [she[ ['s] [nutzo]

pointed criticisms/complaints

- [that/this/it] [is/was] [absolute-

ly/extraordinarily/unspeakably/etc.][bad/rubbish/

crap/horrible/terrible/etc.]

unpalatable questions and/or presuppositions

- why do you make my life impossible?

- which lie are you telling me?

- what's gone wrong now?

- you want to argue with me or you want to go to jail? 
condescensions (see also the use of "little" in Insults)

- [that] ['s/ is being] [babyish/childish/etc.]

message enforcers

- listen here (preface)

- you got [it/that]? (tag)

- do you understand [me]? (tag)

dismissals

- [go] [away]

- [get] [lost/out]

- [fuck/piss/shove] [off]

silencers

- [shut] [it]/ [your] [stinking/fucking/etc.]

[mouth/face/trap/etc.]

- shut [the fuck] up

threats

- [I'll/I'm/we're] [gonna] [smash your face in/beat the shit out of you/box your ears/

bust your fucking head off/straighten you out/etc.] [if you don't] [X]

- [you'd better be ready Friday the 20 th to meet with me/do it] [or] [else] [I'II] [X]

- [X] [before I] [hit you/strangle you]

negative expressives (e.g. curses, ill-wishes)

- [go] [to hell/hang yourself/fuck yourself]

- [damn/fuck] [you]

(Culpeper 2011, pp. 135-136)

\section{Analysis}

The data of this study covers twelve episodes taken from three talk shows, four episodes from each. The talk shows are The Opposite Direction, Objectivity, and Issue on Air.

Table (1): instances of impoliteness in the three programs: 


\begin{tabular}{|c|c|c|c|c|c|}
\hline Categories & $\begin{array}{l}\text { The } \\
\text { Opposite } \\
\text { Direction }\end{array}$ & Objectivity & $\begin{array}{c}\text { Issue } \\
\text { on } \\
\text { Air }\end{array}$ & Total & Persentage \\
\hline PNV & 12 & 3 & 1 & 16 & $6.5 \%$ \\
\hline PNA & 53 & 5 & 20 & 78 & $31.9 \%$ \\
\hline PNR & 23 & 0 & 12 & 35 & $14.3 \%$ \\
\hline P3NR & 7 & 1 & 5 & 13 & $5.3 \%$ \\
\hline $\mathrm{PC} / \mathrm{C}$ & 2 & 27 & 8 & 37 & $15.1 \%$ \\
\hline UQ\&P & 4 & 3 & 3 & 10 & $4.1 \%$ \\
\hline Cond. & 2 & 3 & 2 & 7 & $2.8 \%$ \\
\hline ME & 5 & 3 & 2 & 10 & $4.1 \%$ \\
\hline DIS. & 0 & 1 & 0 & 1 & $0.8 \%$ \\
\hline Silen. & 18 & $\mathbf{0}$ & 1 & 19 & $7.7 \%$ \\
\hline Thr. & 10 & 0 & 2 & 12 & $4.9 \%$ \\
\hline NE & 3 & 3 & $\mathbf{0}$ & 6 & $2.5 \%$ \\
\hline Total & 139 & 49 & 56 & 244 & \\
\hline Persentage & $\% 57$ & $\% 20.1$ & $\begin{array}{c}\% \\
22.9\end{array}$ & & $100 \%$ \\
\hline
\end{tabular}

\section{Discussion}

Reading through the brevious table, one notices that insult occupies mor than the half of the impoliteness strategies found in the twelve episode by $\mathbf{5 8 \%}$ divided as follows: PNV. 6.5 \%, PNA. 31.9 \%, PNR 14.3 \%, P3NR 5.3 \%. The remaining $48 \%$ is for the rest of other impoliteness strategies. Examining the four elements of insult, it is noticed that PNA comes in the first place,followed by PNR, then PNV and finally P3NR. In the rank that follows the 'Insult' is one finds 'Pointed Criticisms/Complaints' by $\mathbf{1 5 . 1} \%$ followed by 
'Silencers' by $7.7 \%$. The other impoliteness strategies occupiy the final positions.

\section{Conclusion}

This study handles impoliteness strategies in Arab talk shows quantitatively. The aim of the study is to answer the following questions: What are the most common impoliteness strategies employed by guests in Arabic talk shows?

The study reached the following result: one of the common impoliteness strategies used is insult. The participants applied all the categories of insult mentioned by Culpeper in his model -namely; 'Personalized negative vocatives', 'Personalized negative assertions', 'Personalized negative references', and 'Personalized third-person negative references' but by different rates. In addition, pointed criticisms occuoy the second rank after insult. From this one can conclude that the guists in the selected talk shows cocentrate on personalization and pointed critisism to humiliate partenners, instead of criticsing the issue of the discussion.

References

Culpeper, J. (2011). Impoliteness: Using Language to Cause Offence. Cambridge: Cambridge University Press.

Abbreveatioms

Personalised Negative Vocatives:

PNV

Personalised Negative Assertions:

PNA

Personalised Negative References:

PNR

Personalised Third-Person Negative References: P3NR 
pointed criticisms/complaints:

\section{$\mathrm{PC} / \mathrm{C}$}

unpalatable questions and/or presuppositions:

UQ\&P

Condescensions:

Cond.

message enforcers :

ME

Dismissals:

DIS.

Silencers:

Silen.

Threats:

Thr.

Negative Expressives:

NE 